\title{
A organização do trabalho na era digital
}

\section{The work organization in the digital era}

\author{
Lilia Aparecida KANAN \\ Marina Patrício de ARRUDA
}

\begin{abstract}
Resumo
Atualmente a organização do trabalho se dá sob certas condições sociais, econômicas e culturais influenciadas pelo excesso de informações e tecnologias próprios da era digital. Para discutir tal situação, o presente artigo, uma revisão crítica, buscou conteúdos em livros e artigos que foram selecionados em razão de apresentarem relação entre organização do trabalho-contemporaneidade e transformações do trabalho/trabalhadores-era digital. A partir disto, objetiva-se discutir algumas características da organização do trabalho na era digital, visivelmente marcadas por aspectos antagônicos e complementares. O trabalho é problematizado em meio a essas características de complexidade, cuja dinâmica engloba, ao mesmo tempo, condições de liberdade e de subserviência. Assim, analisar as mudanças que ocorrem na organização do trabalho a partir dos impactos da era digital pode ser significativo para ampliar a reflexão sobre fatos e acontecimentos que vêm modificando o comportamento de trabalhadores e, em uma instância ampliada, da sociedade na qual ele se insere.
\end{abstract}

Unitermos: Ambiente de trabalho; Mudança organizacional; Trabalhadores; Trabalho.

\begin{abstract}
Currently the organization of work occurs under certain social, economic and cultural conditions influenced by the excess of information and technologies of the digital age. To discuss this situation, the present article, a critical review, searched contents in books and articles that were selected due to the existence of a relationship between the organization of work-contemporaneity and transformations of the work/workers-digital era. From this, the aim is to discuss some characteristics of the organization of work in the digital age, which is visibly marked by antagonistic and complementary aspects. Work is problematized in the middle of these characteristics of complexity, which simultaneously includes conditions of freedom and subservience in the dynamic. Therefore, to analyze the changes that occur in the organization of work from the impacts of the digital era may be significant to broaden the debate on facts and events that change the behavior of the worker and, in an extended way, the society where he/she is inserted.
\end{abstract}

Uniterms: Working environment; Organizational innovation; Workers; Work.

\section{A organização do trabalho na era digital}

A era digital é caracterizada pela constante inovação, por descobertas significativas e pela marcante complexidade dos e nos processos de trabalho. É inegável o impacto do microprocessador e das redes de computadores como teia na qual todas as memórias informatizadas permitem o surgimento do coletivo pensante (Lévy, 2000), na qual homem e tecnologia interagem, produzindo novas formas de subjetividade,

$\checkmark \nabla \nabla$

- Universidade do Planalto Catarinense, Programa de Pós-Graduação em Ambiente e Saúde. Av. Castelo Branco, 170, Bairro Universitário, 88509-900, Lages, SC, Brasil. Correspondência para/Correspondence to: L. A. KANAN. E-mail: <lak@uniplac.net>. 
de cognição e de trabalho. O cenário mundial se altera profundamente em decorrência das mudanças contextuais decorrentes deste progresso tecnológico e científico. Credita-se à mudança do trabalho ao longo dos últimos cinquenta anos a produção das maiores alterações vividas pela sociedade. Impulsionada pelo conhecimento, a era digital está mudando os cenários laborais, os valores da sociedade e o relacionamento humano de forma mais profunda, trazendo uma série de implicações.

A inquietação derivada dessa constatação originou o presente artigo de revisão crítica, que objetiva descrever, analisar e discutir conhecimentos já publicados de abrangência temática, cuja função pretendeu sua atualização. Foram consultados livros e artigos nas bases de dados SciELO, Lilacs e Latindex entre os anos de 2000 e 2011. O critério de seleção tanto de livros quanto de artigos esteve relacionado à existência de relação entre organização do trabalho-contemporaneidade, e transformação do trabalho e de trabalhadores-era digital. Foram referidas ainda quatro publicações anteriores ao período definido (Camus, 1942; Dejours, 1992; Demo, 1996; Engels, 1971) em razão de suas contribuições ao tema.

Nesta revisão adotou-se o conceito de organização de trabalho proposta por Dejours (1992, p.25): "por organização de trabalho designamos a divisão do trabalho, o conteúdo da tarefa (na medida em que ele dela deriva), o sistema hierárquico, as modalidades de comando, as relações de poder, as questões de responsabilidade etc.".

O início da discussão ora proposta está assentado no entendimento de que, atualmente, acumular informações e saber utilizá-las passou a ter tanto valor quanto tinha acumular bens materiais há pouco tempo atrás. Sob a égide desta possibilidade, as pessoas vivenciam uma transição paradigmática, na qual os capitais tangíveis passam a ser substituídos pelos intangíveis, mudança que demanda de todos um grande esforço de compreensão deste novo momento de transformação social.

Em nada diferente de países desenvolvidos, o Brasil vive um momento de grandes e profundas transformações decorrentes da realocação da força de trabalho da indústria para os serviços, do trabalho assala-

584 riado para o autônomo, do emprego presencial para o virtual. Advém destes fatos que os novos processos de produção e de prestação de serviços passaram a exigir trabalhadores mais qualificados, o que, em pouco tempo, fez surgir uma nova classe: o trabalhador do conhecimento e da economia mundializada.

Várias atividades antes executadas dentro das empresas, por razões diversas passaram a ser encomendadas ou realizadas fora delas, reduzindo o número de trabalhadores diretamente empregados como assalariados e ampliando o quantitativo de "empregos virtuais". As transformações do trabalho e, por conseguinte, nos demais campos sociais, aconteceram de forma tão acelerada que sequer permitiram às pessoas imaginar que, ao final de um mesmo século, a maior parte dos empregos estaria no setor de serviços.

Decorrente deste amplo processo de transformações, muitos gestores, empresários e administradores perceberam a necessidade de considerar a subjetividade à compreensão do comportamento humano no trabalho; tornaram-se mais conscientes de sua importância, pois aspectos que a evidenciam transcendem o prescrito, os contratos formais ou os regulamentos vigentes; compreenderam que as expressões de sentimentos e emoções e que as condutas e atitudes dos trabalhadores são determinadas por muitos aspectos, dentre eles os sociais, religiosos, políticos, econômicos e morais (Vergara, 2009). Passaram a investir mesmo que timidamente -, na ampliação da satisfação e motivação no ambiente de trabalho, na integração organizacional como fato, na tecnologia e nos recursos voltados às metas organizacionais e à satisfação de clientes, na produtividade e no comprometimento em substituição à lealdade. É indubitável que todos estes fatores favorecem a qualidade de produtos/serviços e apontam para a exigência de ambientes de trabalho mais agradáveis, ainda que, não raro, a razão que orienta os dirigentes a tornar o ambiente de trabalho mais agradável seja a expectativa de maior produtividade e, consequentemente, maior lucro. Portanto, embora nem sempre norteados por um genuíno interesse nas pessoas, é provável que sejam eles os catalisadores dos processos de mudança em curso (Kanan, 2010).

Essas transformações alcançam um grande contingente de trabalhadores. Com a adoção das novas tecnologias virtuais e digitais altera-se a organização 
do trabalho, abrindo frentes especializadas, inclusive para aqueles que hoje se encontram excluídos do mercado de trabalho. Logo, se as pessoas não estiverem minimamente conectadas à Internet, tornam-se obsoletas muito rapidamente. Essa máxima comumente professada nos dias atuais, embora possa ensejar angústia e sofrimento, também oportuniza ações e decisões pessoais e profissionais mais criativas e o desenvolvimento de habilidades para os novos processos que impactam a organização do trabalho. Esse fato representa contraponto à imobilidade, conservadorismo e centralização que tão explicitamente marcaram o trabalho no século XX.

Em razão desse novo cenário, novas competências são requeridas àqueles que pretendem administrar, participar e atuar ativamente nesse mercado de trabalho altamente competitivo, de concorrência acirrada e com grande grau de incertezas face às mudanças cada vez mais rápidas e constantes. Sob este aspecto, é tanto atual quanto oportuno referir Heráclito de Éfeso (aprox. 540a.C. - 470a.C.), filósofo pré-socrático considerado o 'pai da dialética', que há mais de dois mil anos já afirmava não haver nada mais permanente do que a mudança.

A inconstância que caracteriza os tempos atuais origina e é originada pelas alterações no processo de produção do capital e suas repercussões no processo de trabalho: as várias e, por vezes, contraditórias dimensões que o caracterizam criam e subordinam, humanizam e degradam, libertam e escravizam, emancipam e alienam, e continuam mantendo o trabalho como questão axial em nossas vidas (Antunes, 2005). É possível constatar, então, uma transformação estrutural do trabalho que demanda novas formas de compreensão sobre o mesmo. Decorre que este contexto de mudanças intensas requer um sujeito interrogante e um pensamento cada vez mais complexo, capaz de promover a compreensão da multiplicidade e da diversidade. Em meio a tantas e tão profundas transformações, a era digital propicia o surgimento de um novo paradigma que privilegia o processo e a relação entre múltiplos fenômenos, de maneira que as pessoas, neste contexto, estabelecem ao mesmo tempo relações libertadoras e sacrificantes, que tanto podem emancipá-las, quanto fazê-las padecer.

\section{A complexificação dos processos de trabalho}

O avanço tecnológico propiciou o desenvolvimento das redes de computadores, cujo ícone atual é a Internet. Estas fizeram emergir uma nova cultura, a digital, que, ao promover o acesso à infinita quantidade de informações, determina a incapacidade humana de abarcar, reter e elaborar tanto saber, marca registrada das sociedades informatizadas.

$\mathrm{Na}$ era industrial a hierarquia era mantida pelo controle e centralização do poder. Hoje, há uma tendência à horizontalização das relações de trabalho, com pouca ou mesmo sem hierarquia. Zuffo (2005, p.63) corrobora tal entendimento: "devido à propagação muito rápida de informações, a hierarquia vai desaparecer totalmente e ficará um esquema mais ou menos horizontal de associação. As pessoas serão valorizadas pela sua capacidade, e não pela posição que ocupam".

De certa forma, há uma transformação social em curso, resultado da influência e intensificação de informações (Zuffo, 2002) imprimindo mudanças ao conceito de trabalho. A educação se tornou fator decisivo para o desenvolvimento e a revolução tecnológica que transformou a economia nas últimas décadas e criou um problema para trabalhadores e empregadores. $\mathrm{Na}$ medida em que a economia brasileira se modernizou, os bons empregos ficaram restritos aos mais bem preparados; os demais foram excluídos, passando a atuar no mercado informal - outra tendência dessa época - com baixa remuneração e trabalho precário. Neste ínterim, ganhou destaque a educação, principalmente aquela voltada ao aprendizado contínuo.

A própria modernidade se encarregou de mudar o sentido do trabalho. Na perspectiva psicológica, o trabalho é hoje considerado uma categoria central no desenvolvimento do autoconceito e uma fonte de autoestima (Zanelli, 2010), que alicerça a constituição do sujeito e sua rede de significados.

Hoje, preparar-se intelectualmente é tipicamente trabalho. Por isso a educação foi se tornando essencial, presente na raiz da formação do sujeito histórico, capaz de emancipar-se também pelo trabalho. O que faz do trabalho algo produtivo não é propriamente o esforço físico, mas a inteligência nele investida (Demo, 1996) e a energia pessoal exigida à 
sua realização. É desta forma que o trabalho, em uma era cada vez mais digital, pode ser traduzido pelo termo aprendizado.

Maturana (2000) convida"a uma reconversão de olhar" ao se referir à inexistência de uma realidade independente do observador. Aquilo que o homem observa como lhe sendo exterior não é nada além do que ele mesmo é. Nesse sentido, não há separação entre produtor e produto, sujeito e objeto, trabalho e trabalhador. A unidade autopoiética contém o ser e o fazer, esse é seu modo específico de organização. Poiesis, termo grego, significa produção; por extensão, autopoiese representa a autoprodução. Segundo Mariotti (2000, online) 'a palavra surgiu pela primeira vez na literatura internacional em 1974, num artigo publicado por Varela, Maturana e Uribe, para definir os seres vivos como sistemas que produzem continuamente a si mesmos'. Depreende-se assim que uma unidade autopoética é aquele que é capaz de refazer, de maneira contínua, seus componentes que sofreram desgastes, ou seja, o sistema é simultaneamente produtor e produto.

É nesta medida que referir ao "fazer profissional" significa autorreferência. Nessa nova condição o trabalho passa a ser considerado como um sistema vivo que pode ser descrito apenas em parte. $O$ trabalhador como um sujeito implicado, problematizante e de acordo com seu repertório e suas motivações assume cada vez mais a diligência de seu "fazer". Desta forma, a época contemporânea acena para uma transformação paradigmática da percepção das relações e dos sentidos do mundo. Na era digital, as novas tecnologias não são apenas ferramentas a serem aplicadas, mas processos a serem desenvolvidos pelo trabalhador; por isso, o conceito de trabalho, hoje, passa pela compreensão do conceito de autopoiésis cunhado por Maturana (1997).

\section{O caráter contraditório da inovação tecnológica}

No Brasil, pode-se dizer que a mudança nos padrões de emprego ocorreu de forma abrupta. A partir de 1990, decorrente do impulso de modernização, restou claro um sério problema do Brasil: a educação. Metade da população que trabalhava tinha educação precária, sendo incapaz de operar com eficiência em economias modernas. Qualificar essas pessoas e reunir esforços contra o desemprego foi um dos problemas que a pós-modernidade nos reservou.

As novas tecnologias, ao romperem com a lógica linear requisitando uma lógica pautada na rede hipertextual e no estabelecimento de múltiplas conexões (Lévy, 2000), mostraram que os novos processos de trabalho também reconfiguraram as profissões. Para o autor (p.172), não se trata apenas de "usar as tecnologias a qualquer custo, mas de acompanhar consciente e deliberadamente uma mudança de civilização que questiona profundamente as formas institucionais, as mentalidades e a cultura dos sistemas educacionais tradicionais e, sobretudo os papéis de professor e de aluno". Posturas como esta destacam a relevância do desenvolvimento de programas de inclusão digital como dispositivos de inclusão social. Esse autor considera que a tecnologia pode contribuir para uma sociedade mais justa por desenvolver a habilidade de acessar, adaptar e criar novo conhecimento e possibilidades sociais. Assim, parece que são as habilidades digitais que condicionam as oportunidades individuais, sociais, socioeconômicas, políticas e socioculturais (Demo, 2007).

Em pouco tempo, o trabalho e sua organização passaram por reformulações profundas que favoreceram a configuração de um novo paradigma respaldado por ideias muito diferenciadas como, por exemplo, a desmaterialização da produção e da prestação de serviços. Responder à globalização instou a necessidade de administrar e conviver no trabalho com pessoas de diferentes culturas e com significativa diversidade da força de trabalho (sexo, orientação sexual, idade, raça, religião, etnia, deficiências ou necessidades especiais), bem como de lidar com a temporariedade, com a flexibilidade e com a imprevisibilidade (Robbins, 2009).

No Brasil, somente na década de oitenta as pesquisas sobre a organização do trabalho se proliferam, possibilitando uma multiplicidade de produções com ênfases variadas apontando o caráter contraditório da inovação tecnológica. Entretanto, nos anos noventa as mudanças se acentuaram ainda mais, possibilitando discussões mais profundas na medida em que alguns autores contemporâneos passaram a insistir na perda do significado do processo de trabalho como centro 
da dominação (Antunes, 2006). Sob este ponto de vida, as mudanças nas formas de organização do trabalho suscitaram questionamentos a respeito de outras possibilidades, sinalizando que, para além da perspectiva de alienação e sacrifício, poderia também existir expectativa de liberdade e de emancipação.

Esta breve retomada histórica mostra que em menos de um século os processos de trabalho sofreram profundas transformações. A chamada Terceira Revolução Industrial incluiu nova base tecnológica, nova modalidade de organização e gestão da produção e serviços que permite a globalização do processo produtivo, do sistema financeiro e a formação dos grandes blocos econômicos (Antunes, 2006). A introdução gradativa de máquinas-ferramenta promoveu a substituição da força física do trabalhador, à medida que certas atividades foram absorvidas por artefatos produtivos, que hoje encontram seu protótipo mais avançado no computador. A busca de lucro cada vez maior, mais seguro e duradouro levaria o capitalista a preferir processos produtivos inteligentes. Previa-se, então, que o trabalho como dispêndio de força física recuaria, mesmo no contexto da exploração capitalista (Engels, 1971). E assim, as novas tecnologias como produto humano, que não podem ser pensadas de forma separada do homem, apresentaram também uma característica contraditória: ao mesmo tempo em que se pretenderam poupadoras de mão de obra, também oportunizaram ao homem o repensar de sua própria relação com o trabalho, colocando-o como possibilidade de desalienação.

\section{Um movimento complexo: liberdade e sacrifícios}

A busca da construção de um metaponto de vista para a compreensão das transformações do trabalho na atualidade possibilita perceber que as circunstâncias atuais descrevem as tendências mundiais da complexificação dos processos com destaque a um movimento contraditório que promove liberdade e sacrifícios. O fato é que os valores e os padrões vêm mudando já há algum tempo. Não se trata apenas de uma resposta à exigência da nova organização de trabalho, mas de uma necessidade pessoal de cada profissional resultante da compreensão crítica de um mundo cada vez mais complexo e globalizado. A nova relação que se estabelece com o trabalho se exterioriza visivelmente por meio de mudanças em seus comportamentos: maior interesse pela escolarização (mais anos de estudo), maior senso crítico, posicionamento contra tratamento injusto ou arbitrário, exigência de respeito e espaço para a iniciativa e criatividade, entre outras características que podem ser atribuídas ao seu novo perfil.

Pode-se perceber, assim, que esta nova era está mudando sobremaneira os valores da sociedade e o relacionamento humano (Zuffo, 2005). Por conseguinte, o homem inserido na trama das relações sociais é pressionado por estas necessidades e por novas exigências, porém o que está em pauta é, justamente, uma nova relação com o trabalho e com a organização que o emprega. A contemporaneidade requer novas maneiras para se entabular as relações que no contexto laboral ocorrem. Considerar este alerta representa compreender que a tecnologia, muitas vezes, é vista como impacto, ou seja, como algo arremessado de fora pra dentro. Esta compreensão pode propiciar uma ideia equivocada na medida em que se percebe "uma sociedade como um alvo indefeso".

Esse tipo de pensamento ingênuo, cartesiano, não considera que as técnicas são produzidas pela própria sociedade que, por esta produção, passa a demandar profissionais com novas habilidades. Sob essa perspectiva, o trabalhador é considerado como vítima de um processo capitalista aviltante que apenas o explora. Entretanto, convém assinalar que os homens não apenas fabricam as técnicas como também as utilizam; homem e técnica caminham juntos, um está no outro em uma mesma medida. A tecnologia não é autônoma nem separada da sociedade. Não é externa ao meio e nem age por conta própria.

A perspectiva dialógica trabalhada por Morin (2002) destaca que as pessoas são levadas a considerar as implicações entre sujeito/objeto, homem/técnica. Aqui está presente a ideia de autonomia e dependência. Quando algo acontece em uma parte do todo, tudo se reorganiza/desorganiza. Nesta perspectiva, é possível afirmar que os processos de trabalho na era digital possibilitam o estabelecimento de relações e experiências antagônicas, concorrentes e complementares. Os trabalhadores vivenciam situações de liberdade e de sacrifícios, de autonomia e subserviência, de prazer e de sofrimento concomitantemente. 
As novas tecnologias suprimiram as lacunas e espaços no tempo de trabalho, invadiram em alguma medida a vida pessoal dos trabalhadores, levando-os a experienciar "uma tensão crescente e sem perspectiva de finalização, entre polos contraditórios, em que o sujeito não encontra espaços para a sua realização". (Abrahão \& Sznelwar, 2011, p.103). Convém destacar, entretanto, que as necessidades humanas jamais serão atendidas completamente; em meio a isto, transformar o sofrimento a partir da consciência de suas causas, dos conflitos e das frustrações que os originaram representa comportamento saudável (Mendes, 2004), uma resposta resiliente.

É possível perceber que, na medida em que novas perspectivas de trabalho (aprendizado) se apresentam, a flexibilização no trabalho aponta também para a precarização, adoecimento e para crescentes exigências de qualificação. Diferente do trabalhador que repetia o seu trabalho no ritmo da esteira, na cadência da linha de montagem, em um trabalho totalmente alienante e desumanizante, hoje a sociedade se depara com sistemas que se organizam ora com ares de liberdade, de emancipação, ora com ares sacrificantes. As novas tecnologias, de fato, levaram a uma nova organização dos processos de trabalho. Na experiência virtual, por exemplo, é perceptível uma nova epistemologia. Esta se baseia em ideias bastante diferentes daquelas estudadas até então: a complexidade, o hipertexto, o tempo real, o coletivo pensante, comunicação online, as redes sociais, dentre outras. Trocar experiências e conhecimentos com pessoas do mundo inteiro, assim como visitar bibliotecas, centros de pesquisas, universidades e museus, faz com que a própria perspectiva de mundo e de realidade se modifique, dando lugar à construção de um conhecimento mais global, menos limitado às fronteiras nacionais e imediatas.

\section{Relações de trabalho: o que a era digital tem promovido?}

Grande número de trabalhadores adoece em razão dos reveses causados pela precarização do trabalho, ainda que a mais inusitada tecnologia da era digital esteja presente ou determine seus processos de trabalho. Por exemplo, conforme já mencionado, a atualidade em termos organizacionais é marcada pela elevada transposição de atividade do setor industrial para o setor de serviços. Contudo, o avanço tecnológico, a lógica do self-service, que determina ao consumidor o desempenho de muitas das atividades antes realizadas pelos empregados, além de rarear significativamente as ofertas de trabalho neste setor, promoveu o aniquilamento por meio de infindáveis exigências daqueles que permaneceram, o setor bancário é um bom exemplo deste fato: cada terminal de autoatendimento instalado representou a demissão de muitos funcionários e a ameaça constante de demissão daqueles que permaneceram.

O entendimento de Antunes (2005) sobre uma nova morfologia do trabalho contribui para ampliar as reflexões aqui postas, uma vez que ele destaca que ..."a sociedade capitalista moderna vem ampliando enormemente o contingente de homens e mulheres terceirizados, subcontratados, part-time, exercendo trabalhos temporários, entre tantas outras formas assemelhadas de informalização do trabalho, que proliferam em todas as partes do mundo" (p.143).

Se sob a ótica da organização do trabalho e de seus processos há evidências de arraigadas mudanças, é igualmente importante destacá-las pelo viés do homem que o realiza. Por exemplo, Zanelli (2010) faz referência às pressões sofridas pelos trabalhadores por exigências cada vez mais complexas; atribuição de mais responsabilidades e desempenho aos profissionais; manutenção de colaboradores permanentes em paralelo a um conjunto de temporários; pressões colocadas aos profissionais por aprendizagem contínua e rápida de procedimentos de novas tecnologias e atualização permanente; constantes ameaças de desemprego e vivências de sofrimento no trabalho e, consequentemente, risco de adoecimento; aumento do individualismo em contraposição às solicitações por integração e coesão; comprometimento com a carreira em vez do comprometimento com a organização. Outros aspectos além dos citados pelo autor podem ser acrescidos: informalidade, flexibilização da jornada de trabalho, terceirização e precarização das relações entabuladas neste contexto.

Exigências constantes por maximização de desempenho das equipes de trabalho constituem prer- 
rogativas intrínsecas à função de chefia. Este fato se naturalizou de tal modo que, atualmente, o stress no contexto laboral aparece travestido de estímulo para realização, muito mais do que como sinônimo de doença ocupacional. O discurso recorrente entre os trabalhadores da contemporaneidade concentra ordens para se "administrar" situações estressoras, muito mais do que para eliminá-las, já que tal tarefa se apresenta com hercúlea. Goulejac (2007) sintetiza com clareza o que a este respeito é importante destacar: "o desempenho ilimitado é o motor de um assédio sem fim. Ele gera uma lógica de obsolescência implacável" (p.309). E, ao se submeter às exigências das novas tecnologias e dos sistemas informatizados e padecer em razão dos aspectos dolorosos associados, os trabalhadores "criam estratégias de defesa, como a busca de reificação da relação que, no final de contas, reforça essa ideia de serem programados, de incorporarem um controle que era externo e se torna algo interno, sempre presente" (Abrahão \& Sznelwar, 2011, p.103).

Paralelamente a tais constatações é prudente, neste exercício reflexivo, considerar que o Mito de Sísifo no trabalho, não mais tem espaço para prosperar. Este mito tornou-se conhecido por fazer referência à execução de trabalhos rotineiros, repetitivos, cansativos e que envolvem esforços inúteis - Sísifo, mestre da malícia e dos truques, ofendeu muitos deuses e como castigo, por toda a eternidade, foi condenado a rolar uma grande pedra de mármore com suas mãos até o cume de uma montanha. Sempre que ele estava quase no topo, a pedra rolava montanha abaixo, o que Ihe exigia começar sua inútil tarefa repetidamente (Camus, 1942).

Atualmente, parece ser inimaginável crer que o trabalhador se conforme e aceite um labor que o mantenha preso a um eterno presente, com perspectivas nulas de alteração de seu fazer ou de sua condição de mão de obra. Sob essa perspectiva, é possível encontrar diferentes produções que destacam aspectos positivos presentes na organização do trabalho na era digital. Por exemplo, Boonen (2003), a respeito do uso das tecnologias digitais que possibilitam o trabalho no contexto do lar, identifica a economia de tempo, redução do desgaste físico e psicológico decorrentes do deslocamento e, por conseguinte, menor possibilidade de acidentes de trânsito, maior dedicação aos outros pa- péis desempenhados (pai/mãe), além do tempo mais ampliado para o lazer, o esporte e os cuidados pessoais. O autor defende o entendimento de que a redução do nível de stress, a flexibilização dos horários de trabalho, dentre outros, representam benefícios decorrentes do teletrabalho.

Além destes, encontra-se em Costa (2007) que há uma tendência de reforço à autoimagem destes profissionais como indivíduos responsáveis, comprometidos, independentes e autônomos, o que representa, junto aos mais jovens, uma oportunidade de amadurecimento profissional. Para a autora, a decorrente diminuição do controle direto se traduz em maior autonomia, aumento de responsabilidade e oportunidade de demonstrar competência.

Thiry-Cherques (2007) é enfático ao afirmar que a distinção do trabalho virtual é o profissionalismo emancipado. Para o autor, é a partir do poder de decidir sobre conteúdo/forma do produzir que se convenciona este profissionalismo, vez que a técnica e o controle do próprio esforço estão sob o domínio do trabalhador. Prossegue destacando que "o atributo do trabalho virtual é a autonomia. O seu foco está dirigido para a comunicação, para a interação com os demais trabalhadores e com as organizações" (p.712).

Nesse sentido, o trabalho na era digital enseja ainda outros benefícios: ganhos de tempo e de produtividade devidos às facilidades de acesso à informação; menor distração; maior flexibilidade para organizar o tempo e o espaço do produzir; e alteração no processo de comunicação, antes falha, não documentada e pessoal para uma comunicação sistemática, documentável e formal (Thiry-Cherques, 2007).

É significativo considerar, ainda, que a organização do trabalho em si não consegue imobilizar o trabalhador; tal fato somente acontece quando o controle dos processos inconscientes é fortemente exercido (Antunes, 2006). Independentemente dos benefícios ou dos malefícios anteriormente referidos decorrentes da organização do trabalho na era digital, cabe considerar que existe a possibilidade real de que as demandas decorrentes do aceite e do uso das novas tecnologias produzam perturbações que permitam ao indivíduo acionar sua capacidade de auto-organização e de mobilização para constituir-se num trabalhador reflexivo, pronto para reinventar a si e a seu trabalho. 


\section{Considerações Finais}

Ao discutir as transformações do trabalho na era digital, objetivo deste artigo, observaram-se fenômenos antagônicos e complementares que incidem sobre o ser/fazer/produzir no contexto laboral. Contudo, é pertinente destacar que a organização do trabalho na era digital como um todo mostra, hoje, o trânsito do trabalho manual para o trabalho intelectual; essa mudança fundamental implica a auto-organização do trabalhador, levando-o à autocriação e conferindo-lhe a possibilidade de reinventar seu próprio trabalho.

O trabalho da era digital inclui a compreensão global de um conjunto de tarefas e também exige uma atitude de abertura a novas aprendizagens. As novas tecnologias não são apenas novas ferramentas auxiliares para as atividades tradicionais, mas produto da criação humana. É possível reconhecer que já está em curso um "estilo de vida digital" implementado por rupturas inima-gináveis há algum tempo. O computador, a Internet e as redes são tecnologias da inteligência que, ao ampliar a cognição humana, passam a demandar a ampliação da base educacional que, por sua vez, também influenciará os processos de trabalho daqui para frente. Desta forma, a época contemporânea convida todos a uma transfor-mação paradigmática do trabalho que, por sua com-plexidade, inclui antagonismos e complementaridades ao promover momentos de emancipação, liberdade e sacrifícios.

As ideias aqui apresentadas não procuraram apontar vantagens ou desvantagens da complexificação do trabalho, mas sistematizar alguns entendimentos a partir dos quais é possível compreender de que maneira as técnicas/tecnologias revolucionaram estes processos e, por conseguinte, a vida dos trabalhadores.

A esta discussão interessa que as mudanças irreversíveis deste século pressionam tanto empresários quanto trabalhadores a repensarem a complexidade imposta por um novo conceito de trabalho. De qualquer forma, a complexidade convoca a todos a uma verdadeira reforma do pensamento, uma vez que essa nova abordagem e compreensão do mundo conferem novo sentido ao trabalho e à organização do trabalho, que anuncia renovadas esperanças de menos sofrimento e mais situações de prazer no trabalho.

Por fim, é pertinente considerar que a inesgotabilidade de reflexões a respeito do tema ora tratado é evidente e que se reconhece a importância de novos estudos e pesquisas que ampliem o conhecimento a seu respeito. A insuficiente quantidade de pesquisas empíricas sobre o assunto em foco é limitação identificada que obsta a proposição de um conjunto teórico mais significativo.

\section{Referências}

Abrahão, J. I., \& Sznelwar, L. I. (2011). Entre a tarefa e a atividade, a dor do trabalhar. In A. M. Mendes (Org.), Trabalho e saúde: o sujeito entre a emancipação e a servidão (pp.102-114). Curitiba: Juruá.

Antunes, R. (2005). O caracol e sua concha: ensaio sobre a nova morfologia do trabalho. Asian Journal of Latin American Studies, 18(4), 137-155.

Antunes, R. (2006). Adeus ao trabalho? Ensaio sobre as metamorfoses e a centralidade do mundo do trabalho (11 a ed.). São Paulo: Cortez.

Boonen, E. M. (2003). As várias faces do trabalho. Economia e Gestão, 3(5), 106-127.

Camus, A. (1942). Le mythe de Sisyphe. Paris: Gallimard.

Costa, I. S. A. (2007). Teletrabalho: subjugação e construção de subjetividades. Revista de Administração Pública, 41(1), 105-124.

Dejours, C. (1992). A loucura do trabalho: estudo de psicopatologia do trabalho (5a ed.). São Paulo: Cortez-Oboré.

Demo, P. (1996). Educação e qualidade. Campinas: Papirus.

Demo, P. (2007). Marginalização digital: digital divide. Boletim Técnico do Senac: A Revista da Educação Profissional, 33(2), 05-19.

Engels, F. (1971). Do socialismo utópico ao socialismo científico. Lisboa: Estampa.

Goulejac, V. (2007). Gestão como doença social. Aparecida: Idéias e Letras.

Kanan, L. A. (2010). Poder e liderança de mulheres nas organizações de trabalho. Organizações \& Sociedade, 17(53), 243-257.

Lévy, P. (2000). Cibercultura. São Paulo: Editora 34.

Mariotti, H. (2000), Autopoiese, cultura e sociedade. Recuperado em outubro 12, disponível em <www.geocities. $\mathrm{com} /$ pluriversu/autopoies.html>.

Maturana, H. (1997). Emociones y lenguaje en educación y política. Santiago de Chile: Dolmen Ediciones. 
Maturana, H. (2000). The nature of the laws of nature. Systems Research and Behavioral Science, 17(5), 459-468.

Mendes, A. M. (2004). Cultura organizacional e prazer e sofrimento no trabalho: uma abordagem psicodinâmica. In A. Tamayo (Org.), Cultura e saúde nas organizações (pp.60-76). Porto Alegre: Artmed.

Morin, E. (2002). O método 4: as idéias: habitat, vida, costumes: organização. Porto Alegre: Editora Sulina.

Robbins, S. P. (2009). Fundamentos do comportamento organizacional. São Paulo: Pearson Prentice Hall.

Thiry-Cherques, H. R. (2007). O trabalho individualizado: da venda à dádiva. Revista de Administração Pública, 41(4), 707-731.
Vergara, S. C. (2009). Gestão de pessoas. São Paulo: Atlas.

Zanelli, J. C. (Coord). (2010). Estresse nas organizações de trabalho: compreensão e intervenção baseadas em evidências. Porto Alegre: Artmed.

Zuffo, J. A. (2002). O futuro das profissões e as profissões sem futuro. Recuperado em janeiro 28, 2011, disponível em <http://www.canalrh.com.br/editoriais/entrevistas>.

Zuffo, J. A. (2005). A infoera transformando as relações sociais. Comunicação \& Educação, 10(1), 61-70.

Recebido em: 22/3/2011

Versão final em: 11/4/2012

Aprovado em: 3/5/2012 
